\title{
As sutilezas das faces da violência nas práticas escolares de adolescentes
}

Luiza Mitiko Yshiguro Camacho

UniversidadeFederaldoEspíritoSanto

Resumo

Este artigo busca lançar um olhar sobre a vida escolar de adolescentes de classes médias e de segmentos das elites, incidindo, porém, sobre a prática de violência contra seus pares em duas escolas da cidade de Vitória-ES, sendo uma pública e outra privada.

A pesquisa constituiu-se em um estudo de natureza eminentemente qualitativa, que no entanto valeu-se também de dados quantitativos. No trabalho de campo os dados foram colhidos por meio das técnicas da observação, questionário e entrevistas individuais e em grupos e, também, por meio de depoimentos e da consulta a documentos.

0 estudo permitiu constatar que nas duas escolas investigadas as ações socializadoras incidem muito mais sobre 0 aspecto pedagógico do que na proposta educativa, que é deixada em segundo plano. Onde se constata a ausência de uma ampla abrangência da socialização, aescola não funciona como retradutora dos valores sociais e termina por permitir que idéias de discriminaçãoe precon ceito, porexem plo, in vadam eseestabeleçam no espaço esco lar. A fal ta deal can ceda ação so ci ali za dora até 0 ambiente relacional promove 0 aparecimento de brechas que permitem aos alunos a construção de experiências escolares, dentre elas, a experiência da violência.

Com to dosos en con trose desen con trosen treas esco las, ob servou-se que o ponto decisivo de convergência entre ambas é a presen ça da práti ca da vi o lên cia, ain da que, em in ten si da dedistinta e com faces envolvidas por sutis especificidades.

\author{
Palavras-chave \\ Violência - Escola - Adolescentes.
}




\section{The subtleties of the faces of violence in the school practices of adolescents}

Luiza Mitiko Yshiguro Camacho

UniversidadeFederaldo EspíritoSanto

\section{Abstract}

The proposal of this article is to cast a look upon the school life of middle and upper class adolescents focusing, however, on their practice of violence against their peers in two schools - one public, one private - in Vitória, capital of Espírito Santo, Brazil.

The investigation consisted of an qualitative study, but has also used some quantitative data. In the fieldwork data was gathered through observation, questionnaires, group and individual interviews. Testimonies and written documents were also taken into account.

The work has found that in both schools the socializing actions relate much more to the pedagogical aspect than to the educational proposal, which is left in a secondary position. Whenever a wide-ranging socialization is absent, the school does not function as a re-translator of social values, and ends up allowing ideas such as discrimination and prejudice to invade and overtake the school space. The failure of the socializing action in reaching the relational environment creates gaps through which pupils build experiences such as violence.

With all the similarities and differences between the two schools studied here the decisive converging aspect between them is the presence of violence, even if in different degrees and with their faces veiled by subtle particularities.

Keywords

School - Violence - Adolescents. 
A violência é por natureza instrumental; como todos os meios, ela sempre depende da orienta-

ção e da justificação pelo fim que almeja. E aquilo que necessita de justificação por outra coisa não pode ser a essência de nada. Hannah Arendt, Sobre a Violência

A violência acomete o mundo contemporâneo em todas as suas instâncias e se manifesta de variadas formas. Ela está presente em toda sociedade e não se restringe a determinados espaços, a determinadas classes sociais, a determinadas faixas etárias ou a determinadas épocas. É equivocado pensar que ela se vincula apenas e diretamente à pobreza, aos grandes centros urba nos, aos adul tos eaos dias dehoje. Verifica-se, por exemplo, o crescimento das práticas da violência entre os jovens de classes médias e de segmentos privilegiados da sociedade, nos seus diferentes espaços de atuação: na família, na escola ou na rua.

As reflexões aqui expostas se inspiram numa pesquisa que não investigou os excluídos. Ela envolveu os jovens inseridos na escola, com horas vagas de lazer e esporte e também com possibilidades de atender aos apelos/pressõesdo mundo do consumo - tão importante para ser aceito e "pertencer" a agrupamentos de caráter eminentemente ju venil. Esses sujeitos gozam do direito ao convívio com a família, à inserção na escola e de serem livres da pressão da responsabilidade e da reprodução social. Por outro lado, esses jovens encontram-se à margem do centro do po der, dosli mi tes daspossibilidadesdeesco Iha e ainda submetidos à família e à escola por não serem autônomos financeiramente e não estarem aptos para o trabalho.

Esse estudo sobre a violência praticada por jovens nas escolas capixabas foi realizado em Vitória, no estado do Espírito Santo, uma ci dade de apenas 263.708 habitantes (dado do IBGE, 1996), porque há indicações de que existem razões para tanto. Dois trabalhos realizados recentemente podem auxiliar na elaboração de um rápido retrato da violência nesse Estado. 0 primeiro se refere à segurança nas escolas públicas de todos os estadosbrasileiros, realizado pelo Laboratório de Psicologia do Trabalho do Institu to dePsi colo gia daUni versi da de deBrasília entre 1996 e 1997. Os resultados referentes ao Espírito Santo são surpreendentes e negativos. Essa unidade federativa ocupa o quin to lugar no ranking nacional de ocorrências de roubo e vandalismo, ficando atrás de Pernambuco, Acre, Sergipe e Pará. Dentre os da região Sudeste, o Espírito Santo ocupa o incômodo primeiro lu gar, sen do segui do deM inasGerais, São Paulo e Rio de J aneiro (Codo, 1999).

0 segundo estudo, realizado pela Unesco em 1998, fez um levantamento sobre a violência, entre jovens de 15 a 24 anos, nas capitais brasileiras. ${ }^{1}$ Vitória ocupa o primeiro lugar dentre as capitais brasileiras mais violentas, sendo seguida por Recife, Rio de J aneiro, Aracaju e São Paulo. Os jovens da capital capixaba, do Rio de Janeiro e de Recife têm mais chances de morrerassassinados que os jovens da Colômbia, pois lá a taxa de óbitos foi de 147,3 por 100 mil habitantes. Em Vitória, foi de 164,6; no Rio de Janeiro, de 159; e em Recife, de 154,5.

Apesar da gravidade e da necessidade de reflexões, são muito poucos os estudos existentes a respeito do tema. Em um vasto e apurado levantamento, realizado por Marilia Pontes Sposito (1998), da produção discente nos cursos de pós- graduação em Educação do Brasil, abrangendo o período de 1980 a 1995, foram encontrados somente quatro estudos a respeito da violência que atinge as escolas. ${ }^{2}$

1. Os dados que seguem sobre essa pesquisa realizada pela Unesco foram retirados dos jornais Folha de S. Paulo, de 09/12/1998, e A Gazeta, de 10/12/1998 e atualizados em 2000 com Waiselfisz, J ulio J acobo, Mapa da Violência II: Os jovens do Brasil. Brasília: UNESCO, 2000.

2. Os estudos são: Guimarães (1984; 1990); Guimarães, Maria Eloísa, (1995); Oliveira (1995). A pesquisa realizada por Lia Fukui para a FDE/SEE, entre 1990 e 1991, também deve ser lembrada (Sposito, 1998). A estes estudos somam-se outros mais recentes: as pesquisas multicêntricas realizadas pela Unesco e coordenadas por Waiselfisz (1998) e por Minayo (1999); por Abramovay (1999); a pesquisa que se situa na perspectiva dos trabalhos promovidos pela Unesco, Escola e violência, coordenada por Vera Maria Candau. 
Esse estudo, que articula a violência, a juventude e a escola, vem se somar a ou trosencontrados no Brasil. ${ }^{3}$ Esses trabal hos realizados sobre o tema examinaram escolas públicas, classespo pulares, violên cia dospró priosalu nos contra o patrimônio, contra os adultosecon tra a própria instituição escolar e ações violentas vindas de fora, partindo de ex-alunos ou de galeras ou gangues do bairro. Entretanto, nenhum deles alcançou as práticas violentas contra os pares ocorrendo no espaço intramurosesco la res, nem osalu nos declasses médi ase nem as escolas privadas. Outro elemento que 0 difere dos demais trabalhos é que este desvincula a pobreza da violência, uma vez que a origem social dos responsáveis pelas ações é as classes médias e os segmentos das elites.

Esta pesquisa constituiu-se num estudo de natureza eminentemente qualitativa, apesar de ter utilizado também dados quantitativos. A coleta dos dados de campo se deu basicamente por meio das técnicas de pesquisa: observação, questionário, entrevistas, consulta à documentação e depoimentos. ${ }^{4}$

Mesmo considerando que o fenômeno da violência se manifesta no cotidiano escolar, familiar e nos grupos de sociabilidade, a pesquisa privilegiou a escola. 0 papel dosno vosmo delos de família no processo de socialização e a influência dos grupos de sociabilidade sobre os jovens foram considerados, sim, mas numa abordagem indireta.

A escolha das escolas fundamentou-se nos critérios básicos: de atendimento a alunos de classes médias e segmentos da elite; de uma pertencer à rede pública e a outra à rede privada; de si tu ar-senaci da dedeVitó ria-ES; denão serem consideradas violentas; e de serem referências ou modelos de boas escolas dentro das suas categorias de escola privada ou de escola pública. Assim, as unidades escolares selecionadas foram: uma pública, municipal, que recebe alunos das classes médias; e outra, particular, tradicional e mantida por uma entidade religiosa católica, que, fictícia e respecti- vamente, foram denominadas de Escola A e Colégio $B$.

Houve a definição pelos alunos de 5 a a 8a séries porque, segundo os professores, é nessas séries que incidem os maiores problemas de indisciplina e violência. A pesquisa não se restrin giu a in vesti gar apenas essegrupo isoladamente, porque 0 objetivo era interpretá-los em relação com seus pares e com os adultos. Então, foram investigados, direta ou indiretamente, os alunos, os professores e a equipe técnico-administrativa e os inspetores de alunos.

Os sujeitos sob análise são alunos em idade variando de 12 a 15 anos, com raras exceções para mais ou para menos, nos casos de alunos atrasados ou adiantados para sua série. São adolescentes entran donajuventude.

Alberto Melucci expõe a sua compreensão de adolescência dizendo que ela é um pri meiro momento da juventude e que

não pode ser vista so men tecomo fase detransição entre a infância e a vida adulta, como meta úl ti ma da ma tu ri da de, mascomo um período do ciclo vital no qual há processos específicos de transformação que investem as dimensões mental e corpórea, as relações com os outros e com o mundo. Através dessas mudanças se tornam visíveis uma organização da vida afetiva, modelos de pensamento, formas de relações, que vêm em primeiro plano, renegando temporariamente ao fundo outras partes da experiência. (M elucci e Fabbrini, 1992: p. 25)

3. A violência, assim como a preocupação com ela, não é privilégio brasileiro. Esse problema está disseminado internacionalmente. Dos estudos realizados fora do Brasil, destacam-se os franceses como Éric Debarbieux (1990, 1997, 1998 e 1999), Bernard Charlot (1997), François Dubet (1998), Olivier Galland (1991) e Angelina Peralva (1997 e 1997a).

4. O processo de coleta de dados ocorreu - nas duas escolas - num período de dois anos, ou seja, em 1997 e 1998. A análise foi realizada no ano subseqüente aos da coleta até o início de 2000. As leituras e estudos teóricos ocorreram durante os quatro anos da pesquisa - de 1996 a 1999. 
Para não perder de vista o adolescente sob análise e não cair na armadilha de discorrer sobre uma adolescência abstrata, ele deve ser situado na sua classe social. Esses(as) alunos(as) adolescentes de classes médias em sua grande maioria, com exceções de alguns das classes populares e outros das elites, sofrem forte pressão familiar para serem bem-sucedidos, num momento em que se encontram em uma fase de moratória.

A categoria moratória social merece destaque porqueela explica, com mu itapro priedade, questões sociais da juventude das classes médias e da elite. Estudos sociológicos têm mostrado que a juventude depende de dinheiro e de tempo - uma moratória social - para viver um perío do mais ou menospro lon ga do com relativa despreocupação e isen ção derespon sabilidades. Esse tempo legítimo de permissividade e legitimidade, proporcionado pela família, é aquele dedi ca do a estu darea seca pa ci tar edurante o qual a sociedade os brinda com uma especial tolerância. Mas a moratória é privilégio, geralmente, dos jovens de classes médias, cujas famílias têm a possibilidade de lhes oferecerestudos prolongados e retardar seu ingresso nas responsabilidadesda vida adulta como o trabaIho e o casamento (Margulis, 1996).

Margulis aborda tambéma moratória vi tal, que seria uma espécie de complemento do conceito de moratória social. A moratória vital é crédito temporal, um algo a mais e que tem vinculações com o aspecto energético do corpo. Essa mo ra tó riaseiden tifica com a sen sa ção de imortalidade tão própria dos jovens. Essa sensação e essa forma de se situar no mundo se associam com a falta de temeridade de alguns atos gratuitos; com condutas autodestrutivas, que colocam em risco a saúde que eles julgam inesgotável; com a audácia e o lançar-se em desafios; e com a exposição a acidentes, e a ex cessos de todo tipo. A esse respeito corre a mitologia da cultura juvenil de valorizar o morrer jovem, ou seja, morrer jo vem para não en velhecer, para permanecer sem prejo veme, portan to, imortal. Essa moratória é comum aos jovens de todas as classes sociais e está vinculada à idéia do risco.

A classe social dos sujeitos sob análise deve ser considerada porque ela, dentre outros fatores, é, também, responsável pela construção da identidade, pelas formas de so ciabilidade e pelos modelos que regem suas vidas.

A classe social em análise é freqüentemente anunciada no plural pela diversidade de agrupamentos que ela abrange. ${ }^{6}$ Francisco de Oliveira (1988) se refere metaforicamente às classes médias como a cabeça da Medusa, porque, assim como desta nascem mil serpentes, também na sociedade surgem classes médias com formas, expressões, ramificações e aparências multiplicadas e diferenciadas. Tentar definir o que são as classes médias é um problema porque há uma imprecisão decorren tedo fato deelasserem hetero gêneas.

Num estudo como este, que aborda questões educacionais, há que se reconhecer, como já indicou Angelina Peralva (1985), a importância do estudo clássico de Wright Mills (1976), pois ele afirma que a moderna divisão de trabalho exige uma especialização de competências. Com essa afirmação, Mills está indicando que a escola é a responsável por essas diferentes qualificações e competências. A nova classe média analisada por Mills se insere no mercado de emprego graças a uma passagem mais ou menos prolongada pela escola (Peralva, 1985). Os alunos das classes médias, cientes disso, fazem da escola um instrumento para concretizar seu projeto. Esses alunos tendem a estabelecer uma relação pragmática com a escola (Dubet, 1991).

5. Sobre a moratória, conferir também Erik Erikson, 1987.

6. Angelina Peralva em sua tese de doutorado, intitulada A classe média rediscutida - uma história de lutas no Brasil , defendida em 1985, faz uma discussão teórica a respeito da questão da multiplicidade da compreensão da classe média colocando três grandes interrogações: qual classe média? camadas médias ou classes médias? classe média ou classes médias? 
Maria Alice Nogueira (1991 e 1998) traz valiosas contribuições, com seus estudos sobre as estratégias e comportamentos das famílias pertencentes a diferentes classes sociais em relação à escolaridade e ao destino profissional de seus filhos. Segundo a autora, o comportamento de escolha da escola adotado pelas famílias varia de um grupo social para outro. As elites optam pela escola privada e utilizam estratégias "de distinção" a fim de assegurarem aos filhosafreqüên cia em esta beleci mentosaltamente seletivos e prestigiosos. As classes médias, quando podem, optam pela escola particular, mas quando não, partem para a escola pública escolhida e utilizam as estratégias "de evitamento", ou seja, evitam certas unidades escolares situadas em bairros populares, com clientela de nível socioeconômico baixo e/ou com ensino de má qualidade. Essas duas situações de escolhas das escolas foram verificadas nas famílias das duas escolas investigadas.

A opção, neste trabalho, pelo termo "classes médias", no plural", deve-se às indicações da pesqui saem pírica. Asesco laspesqui sadasapresentamcontextosesu jeitosdiferenciados; as famílias são de segmentos diversos; os alunos se reconhecem como pertencentes às classes médias, mas com sociabilidades, estilos, consumo e projetos distintos. Entretanto, é preciso esclarecer que os alunos não formam um grupo homogêneo de classes médias. Pelo contrário, a heterogeneidade transpareceu, pois foram verificados alguns alunos provenientes das classes populares na escola pública e uma pequena parcela pertencente às elites no colégio privado.

De que violência se fala aqui? Ao analisar o fenômeno da violência, deparamo-nos com uma série de dificuldades. Uma delas se refere justamente a essa multiplicidade de compreensões a seu respeito. Essadiversidade evidenciaa fragilidade das suas fronteiras. A violência se confunde, se interpenetra, se inter-relaciona com a agressão de modo geral e/ou com a in- disciplina, quando se manifesta na esfera escolar.

A fragilidade das fronteiras entre a indisciplina e a violência mostrou-se evidente na pesquisa empírica, o que fez com que os rumos das preocupações se alargassem: não era possível iso laro fenô meno da vi o lên ciado dain disciplina. Dessaforma, aspráticasdaindisciplina, constantemente citadas, e mesmo confundidas com condutas de violência pelos sujeitos e protagonistas - os alunos -, passaram a ser observadas com atenção.

Paracom preen deraquestão dadisci plina no âmbito da socialização vale recorrer a Émile Durkheim (1925). A criança, aos seus olhos, é um ser marcado pela ausência porque Ihe faltam qualidades morais, consideração em relação aos interesses dos outros, isto é, faltam-Ihe condutas recomendadas para a convivência social. Para suprir essas ausências, os adultos devem lançar mão da educação, transformando essa criança, por meio da socialização, num ser social e moral, com sua natureza neutralizada. 0 "mal" originário da natureza deve ser contido pela disciplina que imporá limites morais.

A noção dada por Durkheim sobre disciplina comporta os mecanismos de regularidade, autoridade, limite, penalidade, culpa e recompensa. Por meio da regularidade e da autoridade, os limites são definidos para as crianças. E, para completar o processo, as pu nições e as recompensas garantem o respeito às regras. A punição repara a falta cometida, mas serve mais para dar uma satisfação ao obediente do que para normalizar o transgressor. É por isso que a punição deve ser pú blica. Já a recompensa é o contraponto do castigo, mas ela tem peso menor que a punição.

7. As classes médias abordadas nessa tese são compreendidas seguindo-se critérios econômicos complementados por outros, políticos e culturais. Aqui são considerados a acumulação, 0 conhecimento e o modelo cultural, como o fez Angelina Peralva (1985), que por sua vez inspirou-se nas idéias de Alain Touraine (1973). 
E o espaço mais apropriado para tornar a criança um ser disciplinado é a escola, porque nela

Existe todo um sistema de regras que determinam a conduta da criança. Ela deve se apresentar à classe na hora fixa, uniformizada e numa atitude conveniente; na classe ela não deve atrapalhar a ordem; ela deve aprender suas lições, fazer seus deveres, os deve fazer com uma suficiente aplicação, etc... Há assim uma multiplicidade de obrigações às quais a criança está forçada a submeter-se. Seu conjunto constitui o que se chama disciplina escolar [grifo meu]. Pela prática da disciplina escolar é possível inculcar na criança o espírito de disciplina. (Durkheim, 1925, p. 169)

Mas é sabido que a esco la, hoje, está passando por uma criserelacionada à socialização, e ela tem enfrentado dificuldades na transmissão das normas e dos valores gerais da sociedade. Além disso, a escola regida pelo modelo tradicional, com o manejo de classe nas mãos exclusivamente do professor e os alunos em posição de obediência e subalternidade, perdeu-se no tempo. A sala de aula onde vigoram novos modelos de relações entre professores e alunos, onde tudo pode ser passível de discussão, onde a hierarquia fica menos visível, onde os alunos têm o direito de opinar, é uma nova realidade. Esses novos modelos, com capacidade de maior elasticidade de tolerância, implicam novas definições de disciplina.

Assim, mesmo reconhecendo o valor e as contribuições do legado de Durkheim à educação e, acima de tudo, que os ideais da escola tradicional ainda estão fortes e presentes no cotidiano de muitas escolas, é necessário ir além e buscar novos caminhos para compreender a indisciplina na escola.

0 termo indisciplina não pode se restringir apenas à indicação de negação ou privação da disciplina ou à compreensão de desordem, de descontrole, de falta de regras. A indiscipli- na pode, também, ser entendida como resistência, ousadia e inconformismo. Essa compreensão de indisciplina está vinculada ao entendimento do processo educativo enquanto processo de construção do conhecimento, no qual emergem falas, movimento, rebeldia, oposição, inquietação, busca de respostas por parte dos alunos e dos professores. Mas, mesmo nesse sentido positivo, a indisciplina incomoda, porque a escola não está preparada, de fato, para conviver com cenas em que o professor não tem mais 0 controle total e em que cada aluno tem o seu querer.

A garantia da manutenção da disciplina na escola sempre exigiu a presença das relações de dominação e subordinação. Houve, entretanto, uma mu dan çana correlação en tre as partes. Os alunos adquiriram maior espaço de atuação e de decisão, mais autonomia, e se fortaleceram. Na mesma proporção em que há mais igualdade, as situações de tensão se evidenciam, já que os alunos têm possibilidades de se exprimir. As tensões podem ser geradas nas relações de obediência às regras impostas ou no confronto com as diferenças culturais, sociais, econômicas e/ou geracionais.

Não existe apenas um ponto de vista absoluto sobre determinado fenômeno, mas há o ponto de vista de observadores. 0 outro estásituado diferentemente de mim e por isso tem outros va lo res, ou éti ca ou ex periên cia de mundo. Ao analisar-se a indisciplinado ponto de vista, por exemplo, apenas do adulto, tende-se a enquadrá-la no rol dos delitos, da má ação, do que requer punição. Em contraparti$\mathrm{da}$, se nos ativermos apenas ao olhar do aluno, isso pode significar a isenção da responsabilidade de seus atos, já que não agem intencionalmente contra o outro, mas apenas buscam a emoção, o divertimento, as sensações diferentes ou o desvelamento de novos sentimentos.

A captação de diferentes perspectivas possibilita uma infinidade de compreensões 
de indisciplina. Mas, ao pensar a indisciplina, há que sempre se lembrar do seu lado positivo. M uitas vezes, ela se torna instrumen to deresistência à dominação, à submissão, às injustiças, às desigualdades e às discriminações em busca da identidade e dos direitos (cf. Apple, 1989, Camacho, 1990). Há de se considerar também que a compreensão da indisciplina acompanha as mudanças através dos tempos e nos diferentes lugares. A elasticidade da permissividadeno tempo e no espaço torna as fronteiras da indisciplinamaleáveis, frágeisedifíceis deserem definidas. É por isso que muitas vezes ela se confunde com a violência ou com a agressão.

A mesma variabilidade de concepçõesencontrada para indisciplina também é verificada para se conceituar o fenômeno da violência. Tal diversidade se justifica por dois motivos: primeiro porque o seu entendimento não é o mes mo nos diferentes períodos da humanidade e, segundo, porque cada pessoa interessada no tema pode se permitir compreendê-la conforme os seus valores e a sua ética.

Etimologicamente, violência vem do latim vis, força, e significa todo ato de forçacontra a natureza de algum ser; de força contra a espontaneidade, a vontade e a liberdade de alguém; de vio lação danatu reza deal guém ou de alguma coisa valorizada positivamente por uma sociedade; de transgressão contra aquelas coisas e ações que alguém ou uma sociedade define como justas e como um direito; conseqüentemente, violência é um ato de brutalidade, sevícia e abuso físico e/ou psíquico contra alguém e caracteriza relações intersubjetivas e sociais definidas pela opressão, intimidação, pelo medo e pelo ter ror (Cha ui, 1998 e 1999).

As leituras que deram suporte para este estudo sobre a violência escolar foram principalmente de pesquisadores da França, como Bernard Charlot (1997), Éric Debarbieux (1990, 1997, 1998, 1999) e Angelina Peralva (1997,1997a), François Dubet (1998) e Olivier Galland (1991). Os três primeiros têm tomado como referência as idéias de Norbert Elias
(1996) a respeito do processo civilizador, quando denominam as pequenas violências ou as pequenas agressões do cotidiano que se repetem sem pa rar, a fal ta de po li dez, a transgressão dos códigos das boas maneiras ou da ordemestabelecida, dein ci vilidades, paraefeito de distinção das condutas criminosas ou delinqüentes.

Charlot (1997), ao investigar a violência nas escolas francesas, sintetiza a tese de Elias, afirmando que a violência seria um conjunto de incivilidades, ou seja, deaten ta doscotidianos ao direito de cada um ver sua pessoa respeitada. Ele indica que o homem, por sua condição antropológica, é obrigado a aprender a ser homem. Já que nasce imaturo, ele só pode se ho mi ni zarse for ca paz de seapro priar daquilo que a espécie humana cria no curso de sua história. Desde que ele aprende, se hominiza, ele entra numa relação que está sempre em marcha com o mundo, com o outro e consigo mesmo. As pesquisas por ele coordenadas indicaram que a tensão cotidiana tem aumentado bem mais que a violênciaenten dida como agressão fí si ca. "Essa ten são se mantém e exacerba a incivilidade; e explode sob a forma de crises - injúrias, rixas, tumultos, pancadas, etc." (1997, p.20). Além de ser maior, essa tensão propagou-se pelas escolas que, há alguns anos, eram consideradas seguras.

Esta premissa de que a violên ciadecorre da falta de controle sobre as condutas e da ausência da civilidade incorpora a idéia de fundo de que é a civilização que canaliza eestabelece a contenção dos instintos. Parte dessa premissa também a idéia de que a escola, responsável pela hominização, deve "civilizar" os alu nos, deforma alevá- losa con tro lar suas condutas, suas emoções e seus impulsos agressivos.

No entanto, a escola não tem cumprido seu papel de hominizar porque sua função so cializadora não se tem evidenciado, provocando, assim, um espaço onde o aluno tem 
construído uma experiência de violência (Dubet, 1991, 1994, 1995). Em razão dessa crise, as práticas de violência têm pipocado cotidianamente entre os alunos. Além disso, acredito que essas violências "leves", não-físicas, verbais e com outras formas de manifestação - como segregação, exclusão, indiferença -, não são assu midas, fican do disfarçadasou mascaradas.

Para explicar a cegueira a determinados tipos de violência praticados por determinados setores (geralmente dos dominantes) contra outros segmentos (dos dominados) são utilizadas as idéias de Marilena Chaui (1998 e 1999) sobre a dificuldade que há no Brasil em compreender e até em enxergar a violência real. Segundo ela, vivemos uma situação paradoxal, porque, deum lado, bra da-secon tra a vi o lên cia e a favor de um "retorno à ética" e, de outro, são produzidas imagens e explicações para a violência que impedem a visibilidade e a compreensão da violência real. A violência real é ocultada por mecanismos ou dispositivos ideológicos como os da exclusão, da distinção, do ju rídi co, do so ci o ló gi co eda in ver são do real. ${ }^{8}$

Os mecanismos apontados por Chaui podem au xiliarno examedaspráti cas devio ôen cia dos alunos, bem como na compreensão de determinadas representações correntes nas duas escolas investigadas. Entretanto, aquele que é mais significativo é o da inversão do real, pois ele pode ajudar a compreender situações encontradas nos ambientes escolares, como, por exemplo, a utilização, por alunos ou professores, de artifícios para mascarar os atos violentos, ou então o fenômeno da inversão de posições de discrimina dorem discriminado ede discriminado em discriminador.

\section{As sutilezas das faces da violência}

A instituição escolar tem se ressentido dos limi tesdaso ciali zação pornão estarcon seguin do atu ar nosdois mun dos- do peda gó gi co e do relacional dos alu nos- queresi dem den tro dela. Essa crise da socialização gera um espaço no qual os alunos constroem uma experiência significativa, muitas vezes fora da própria da escola, ou contra ela, ou dentro, mas a despeito dela (Dubet, 1991, 1994 e Dubet e Martuccelli,1995).

Ficou visí vel queasaçõesso cializado ras das duas escolas incidem muito mais no rigoroso aspecto pedagógico. Ambas, da perspectiva do projeto pedagógico, podem ser consideradas bem-sucedidas porque, no geral, os índices de aprovação são altos e as respostasdosalu nostêm sido satisfató rias. Cla ro que é necessário considerar que, na Escola $\mathrm{A}$ (pública), há mais dificuldades, mas mesmo assim, ela é considerada um bom estabelecimento de ensino. No Colégio $B$ (privado), há uma eficácia maior do que na escola pública, porque os professores conseguem transmitir os conteúdos e os alunos conseguem responder melhor. Na Escola A, o sucesso no trabalho pedagógico é menor porque há uma diversidade social maior e o capital cultural dos alunos não se afina tanto com a instituição escolar, então, eles respondem menos, apesar de os professores serem muito bons. A

8. Os dispositivos ideológicos responsáveis pelo ocultamento da violência real apresentados por Chaui são:

- da exclusão - existe um mito de que o Brasil é uma nação não-violenta. "0 mecanismo da exclusão produz uma diferença entre um nós-brasileiros-não-violentos e um eles não-brasileiros violentos. Eles não fazem parte do nós." (p. 36)

- da distinção - ocorre uma distinção entre 0 essencial e 0 acidental. Os brasileiros, por essência, não são violentos e por isso a violência é acidental, superficial, momentânea, uma crise, limitada temporal e espacialmente.

- jurídico - circunscreve a violência no campo da delinqüência e da criminalidade. Esse mecanismo permite determinar quem são os "agentes violentos" (os pobres) e legitimar a ação da polícia contra os pobres, os negros, as crianças de ruas e outros.

- sociológico - considera a violência como um momento de anomia social no qual a perda das formas antigas de sociabilidade ainda não foram substituídas por novas. A violência, aqui, é considerada como um momento no qual os grupos sociais "atrasados" ou "arcaicos" entram em contato com os grupos sociais "modernos", e por estarem desadaptados, tornam-se violentos.

- da inversão do real - são produzidas máscaras que permitem dissimular comportamentos, idéias e valores violentos como se fossem não-violentos. 
escola não apresenta as mesmas condições aparelhadas do ensino do colégio privado.

Os dois estabelecimentos de ensino mostraram-se instituições fortes no aspecto pedagógico, mas fracos na esfera das relações dos alunos, porque nas fibras dessa convivência os jovens das duas escolas vão tecendo uma experiência, que não nasce, necessariamente, do projeto da instituição, ou seja, eles vão construindo um modo de viverden tro do estabelecimento que in depen dedainstituição e que pode até negar a vida da escola. E esse território onde a instituição escolar não está agindo é 0 território das experiências (Dubet, 1994 e Dubet e Martucceli, 1995).

Onde ocorre a ausência de proposta educativa, a escola não funciona como uma retradutora dos valores sociais e termina por permitir que os valores sociais predominantes invadam o seu ambiente sem nenhum filtro educativo. Com isso, marcas como a dos preconceitos, por exemplo, acabam se alojando no interior do espaço esco lar. A fal ta deal can ceda ação socializadora até 0 ambiente relacional promove brechas que permitem aos alunos a construção de experiências escolares, entre elas, a experiência da violência.

Os territórios da experiência da violência são diferentes nas duas escolas, o que não significa que ela não se construa em qualquer espaço, eventualmente. No Colégio $B$, ela surge predominantemente nas salas de aula, diante dos professores, enquanto que na Escola A os episódios mais freqüentes ocorrem nos pátios, nos corredores, na calçada em frente ao prédio. Como na escola religiosa as práticas da violência são tecidas com a presença dos professores, elas ganham disfarces, o que não é necessário na outra escola, onde não há adultos por perto. Assim, há duas formas predominantes de prática desse ato: a da violência mascarada/implícita e a da violência não-mascarada/explícita. É neces sá rio quesefaça um alerta en fáti co parao fato de esses territórios e essas formas ocorrerem predominantemente, 0 que significa que, eventualmente, pode haver mu dan çadeespaços, de faces e de escola.

A partir de um certo momento da pesquisa, a grande indagação passou a ser: quem pratica a violência contra quem e por quê? A investigação foi mostrando duas situações: uma, mais comum na Escola A, em que os agressores eram os diferentes; e outra, mais freqüente no Colégio $B$, em que os agredidos, excluídos e rejeitados apresentavam um ponto em comum - todos traziam alguma marca que os diferenciava da maioria - , fossem elas marcas que os distinguiam culturalmente ou pelo corpo. Surgiu a indicação, também, de que os agressores aos diferentes pertenciam, no geral, aos grupos dos portadores de características socialmente exigidas ou dos "capacitados" a atender aos critérios impostos pelos dominantes. É necessário que se destaque $o$ fato de que as duas escolas apresentaram esses dois tipos de episódios. No entanto, na escola pública é mais marcante a violência sendo praticada pelos diferentes, e, na religiosa, sendo dirigida aos diferentes.

Observou-se que a intolerância ao diferente ocorre nas duas escolas, mas em proporções diferenciadas. $\mathrm{Na}$ Escola $\mathrm{A}$, ela é difusa e eventual, ao passo que no Colégio $B$ ela é forte eseconstitui no prin ci pal nascedou ro da prática da violência ao diferente. As razões estão, primeiro, no fato de que os alunos da escola religiosa estão muito bem integrados nos seus grupos e movidos pelo desejo de fidelidade, 0 que abre possibilidades de rejeição aos intrusos/de fora/diferentes. 0 outro motivo dessa rejeição é o mecanismo que transforma o diferente no desigual/inferior (Pierucci, 1999). Essa compreensão de desigualdade encontra fácil penetração nesse estabelecimento, por ter ele próprio, enquanto instituição, a presença muito forte da idéia e da prática da hierarquia. Efinalmente, os alunos pertencem às classes médias, com segmentos da elite, o que facilita 0 auto-reconhecimento de alguns, de serem superiores e destacados dos demais da sociedade. 
A realidade que se apresenta nas duas escolas, mas com maior ênfase na unidade privada, no que se refere ao tratamento dado à diferença, possui duas faces: de um lado, há as razões sociais da diferença, que geram intolerância, preconceito, discriminação, racismo e violência porque, nesse caso, a diferença é con siderada desigualdade e não diversidade. De outro lado, há a dificuldade típica do momento da idade (adolescência) de se lidar com as diferen ças. Essesalu nos, por esta rem num pro ces so de busca de afirmação da identidade, tendem a rejeitar aqueles que não pertencem ao seu grupo e que apresentam características diferentes das suas (Erikson, 1987).

Nas duas escolas existem variados momentos e diferentes formas de práticas violentas dos alunos: as práticas da violência mascarada e as práticas da violência não-mascarada ou explícita. Esse mascaramento, como já foi dito anteriormente, pode ser explicado por meio dos mecanismos ideológicos que permitem a ocultação da violência real apontados por Marilena Chaui (1998 e 1999). A ocultação da violência foi verificada, com mais força, no Colégio B o que não significa que não se possa, eventualmente, encontrar o mascaramento na pública e o não-mascaramento na religiosa.

A violência, na sua forma explícita de manifestação nas escolas, é combatida, criticada e controlada por meio de punições. Entretanto, a violência mascarada passa impune, ou porque não é percebida como tal e é confundida com a indisciplina, ou porque é considerada pouco grave, isenta de conseqüências relevantes, ou, finalmente, porque não é vista.

As medidas de repressão da violência adotadas pelas escolas são, muitas vezes, dribladas pelos alunos. A pesquisa revelou pelo menos duas maneiras encontradas pelosalunos para se desvencilhar das punições destinadas à contenção da vio lên ciavisível. A primei radelas, bem antiga e utilizada pelos alunos há muito tempo, se dá com a transferência do confronto para um espaço livre de repressão. Explicando: as desavenças que se iniciam nas dependências da escola ficam, normalmente, circunscritas a ameaças e agressões verbais. 0 que não se resolve com palavras é levado para fora dos muros escolares, onde os alunos fazem os acertos de contas com agressões físicas. A segunda maneira encontrada pelos alunos para burlar o controle da violência é, justamente, 0 mascaramento da ação.

Por ser vi sível, a vi o lên cia explícitaé, na maioria das vezes, assumida, combatida, punida e evitada, mas há as exceções, como, por exemplo, as depredações na Escola A, que, de tãobanalizadas, já não são mais percebidas. $A$ violência mascarada, por outro lado, passa, quase sempre, a ser confundida com indisciplina ou com brincadeira. É considerada menos grave, porque não traz conseqüências vi síveisou deefei to imediato, porquenão machu ca o cor po, não faz ver ter o san gue. Os danos, muitas vezes indeléveis, são, geralmente, de ordem psicológica e/ou moral.

Essa violência pode se tornar perigosa porque não é controlada por ninguém, não possui regras ou freios e porque passa a ocorrer constantemente no cotidiano escolar. De tanto acontecer, ela passa a ser banalizada e termina por ser considerada "naturalizada", como se fosse algo "normal", próprio da adolescência. A banalização da violência provoca a insensibilidade ao sofrimento, 0 desrespeito e a invasão do campo do outro.

A ideologia dos tempos contemporâneos, que prega o individualismo exacerbado, que nega e até combateasini ciativascoletivas, faz com que o sujeito não enxergue o outro. 0 outro é o diferente, é o estranho, é o nada. 0 que tem valor é o "eu" e aqueles com os quais o "eu" se identifica. 0 outro não desperta a so lidariedade, o respeito, o bem-querer, e pode, por qualquer motivo banal, ser destruído, eliminado, segregado e excluído.

A falta de limites, a falta de responsabilidade pelos atos praticados e a desconsideração pelo outro movem os adolescentes na 
direção de atos de imposição pela força, de agressão e de destruição, porque, primeiro, eles desconhecem os limites do até onde podem ir e quando devem parar; depois, estão convencidos de que ficarão impunes, já que não são res ponsáveis pelos atos que praticam, porque estão sempre "brincando" e nunca têm a intenção real de machucar, queimar ou matar, e, finalmente, o outro é diferente e não apresenta significado.

A investigaçãomostrou que o fundamento básico da forma de expressão mascarada da violência contra os diferentes é a discriminação, nas suas variadas modalidades. Foram observadas práticas de intolerância em face dos diferentes, concretizadas nas formas de discriminação so cial (aospo bresou ricosdema is), racial (aos negros), de gênero (aos homossexuais) e aos que se distanciam dos padrões colocados (aos bons alunos, aos maus alunos e aos novatos na escola, aos gordos, aosfei os ${ }^{9}$ eou tros).

A discriminação social foi percebida nas duas escolas, mas com variações quanto à intensidade. No estabelecimento privado, ela é generalizada, acentuada, constante e atinge, não apenas os alunos, mas também professores e funcionários. Os professores, por exemplo, notam 0 tratamento diferenciado dos alunos conforme suas posses: se apresentam indícios de riqueza como jóias e roupas de griffe, ou freqüentam locais reservados à elite, como determinados clubes, por exemplo, são tratados pelos pais e alunos como iguais. Caso contrário, são desprezados e considerados inferiores. $\mathrm{Na}$ escola pública, esse tipo de discriminação é mais brando, restringe-se a apenas alguns praticantes e é, portanto, mais difuso.

No Colégio $B$, a expressão da violência aos etnicamente diferentes é mais freqüente que na Escola A, da mesma forma como ocorre com a discriminação social. No entanto, a demonstração crua e direta do racismo, nessa unidade privada de ensino, não é prática generalizada. Há aqueles que a escondem por trás da "brincadeira". Os adultos reconhecem que esse tipo de prática de discriminação se apresenta mascarada na forma de brincadeira.

$\mathrm{Na}$ Escola A, as práticas da discriminação racial são vela das. Elasatin gem princi palmente os alunos de origem negra, mas os poucos de origem asiática também não são poupados. Aqui, também, os que a praticam tendem a caracterizaros atos como brincadeira. Aqueles que praticam esse tipo de discriminação apresen tam duasformas decon du ta: ou a negam ou a admitem. Aqueles que a negam o fazem sem convicção, demonstrando desconforto, como se a negação significassea real ausência da discriminação. Entre os que a admitem, incluem-se aqueles que, contraditoriamente, dizem que é discriminação, mas que é, também, simples brincadeira.

0 preconceito em relação aos homossexuais, que embasa as expressões de discriminação, se faz presente na sociedade em geral. As escolas, instituições sociais que são, não fogem desse quadro e apresentam, igualmente, esse preconceito. Ele se exterioriza na forma mais direta e mais constantemente na Escola A. No colégio privado, ele existe mas é sobrepujado pelas discriminações sociais e raciais, colocando-se, dessa maneira, num segundo plano.

Os alunos que fogem dos padrões médios de apro veitamen to - tan to para mais, sendo bons alu nos, como para menos, sen do maus alunos - não são aceitos pelos seus pares nas duas escolas. Mas são alvo de ações discriminadoras também aqueles com comportamento adequado demais às normas disciplinares.

Em variadas circunstâncias e nas duas escolas verificou-se que 0 aluno pode ser indisciplinado, displicente nos estudos e violento sem que isso o desmereça diante dos

9. A utilização de adjetivos qualificativos como feio, bonito, gordo, magro, tem como parâmetros os padrões estéticos dos sujeitos investigados. É sabido que bonito ou feio, gordo ou magro, são conceitos muito relativos, porque dependem do gosto individual, da época e do espaço. 
colegas, pelo contrário, isso até o valoriza. 0 inadmissível é que ele seja reprovado. Está aí um dos motivos que levam os alunos das duas escolas a temer a reprovação que traz - além das conseqüências já conhecidas como a repetência da série e a frustração da família - a rejeição do seu grupo de pares.

Há a tendência, entre os alunos, de relacionar bom rendimento escolar com homossexualidade. Ser estudioso e disciplinado é ser homossexual. A "macheza" está diretamenteli gada à coragem de transgredir, de agredir e de não estudar, mas tendo a competência de ser aprovado, mesmo que seja utilizando-se de ou tros subterfúgios que não a dedicação ao estudo. Essa ideologia é plantada por aqueles que impõem seu poder na base da força, da ameaça e da agressão. Os que apresentam aproveitamento inferior, a ponto de incorrer na retenção na mesma série, são passíveis de recusa do pró prio grupo. E, para agravar, esses alunos sofrem, também, a rejeição dos professores. Os comportamentos de rejeição aos bons alunos são an ti gosenem po dem sercon si dera dos graves. Entretanto, essas velhas atitudes ganham, atualmente, novos tons. 0 específico de hoje são os limites tênues para essas condutas, em que pequenas discriminações, que sempreexistiram, descambam, rapidamente, para uma situação explosiva. Quando os controles do sistema sobre a disciplina e as regras são mais fracos e os espaços democráticos não são utilizados de maneira adequada, essas práticas antigas e comuns ganham colorações e, freqüentemente, passam fácil e rapidamente para o território da violência.

Os grupos já formados nas duas escolas mostraram-se tendentes a rejeitar os novatos movidos pelo pensamento de que "eu e meu grupo nos identificamos entre nós, mas o novo é diferente de mim e de nós". A presença do no vato pode, ainda, fa zer aflo rar aqui lo queseassemelha à defesa do território, ou seja, como se os já sediados desejassem mostrar quem são os donos do pedaço. Há que se reconhecer que a defesa do território é inerente à sociabilidade juvenil. Entretan to, ascon du tasqueul trapassam a normalidade ganham gravidade quando a isso se juntam situações amplas de preconceito, discriminação e recusa do novo diferente.

As duas escolas mostraram nuanças no que concerne a essa forma de discriminação. $\mathrm{Na}$ Esco la A, as ações vi o len tas são mais ex plícitas, radicais e se concretizam na forma de intimidações, surras e extorsões. No Colégio $B$, as manifestações ocorrem de maneira mais sutil e mais dissimulada nas formas de segregação, de desmerecimento e de desrespeito, mas, apesar disso, são percebidas pelos alunos.

Osado lescen tesprecisam da for mapara poderem se entender como pessoas. Por estarem envolvidos no processo de construção da identidade, a forma ému i to im portan teepassa a ser essencial. A aparência física pode definiruma série deco i sas, como servalo rizado/desvalorizado/ridicularizado, aceito/rejeitado, amado/desprezado, perseguido/bajulado, ou seja, pode definir se ocorrerá uma discriminação positiva ou negativa.

A adolescência é uma etapa da vida na qual ocor rem gran des transfor ma ções decondutas, cognitivas, emocionais e fisiológicas e, conseqüentemente, é um período no qual a imagem do corpo também se encontra em plena mudança. 0 jovem é portador de um corpo em constante transformação e a aceitabilidade desse corpo depen de, em gran de parte, dos critérios legitimados pelo seu grupo de pertencimento. A autoconsciência do adolescente se traduz numa auto-observação e num constante exame de suas qualidades físicas (Valiente, 1996).

Nessa fase da vida há uma certa confusão quanto à imagem corporal. Há, também, uma supervalorização do corpo, que pode se traduzir na busca do impacto pela estética ou pela antiestética. Tanto uma como a outra se manifestam por meio de roupas, penteados, 
marcas como tatuagens ou piercings, etc. (Zimerman, 1999). Há aqueles comportamentos, valores e idéias que são próprios da adolescência e, por isso, considerados normais e esperados. Entretan to, háaquelesqueo so cial reforça e que trazem muito mais sofrimento hoje do que tempos atrás. Um exemplo do social reforçando essa tendência própria dos jovens é 0 fato de a sociedade contemporânea privilegiar o culto ao corpo magro e saudável e com isso acabarestimulan do o desenvolvimento de con dutas cujo eixo central é o próprio corpo.

A obesidade, a baixa estatura, a cor da pele mais escura, e tantos outros desvios dos padrões aceitos socialmente são motivos de discriminação, de exclusão, de auto-isolamento, de sentimento de rejeição, de baixa auto-estima, enfim, de muito sofrimento para os adolescentes. Isso se o problema for observado do ponto de vista do "desenquadrado" dos padrões. Mas observando-se da perspectiva dos devidamente "perten cen tes" eacei tospelo grupo de iguais, constata-se a discriminação e a rejeição aos que são diferentes e que não se identificam com os padrões propostos.

Dentre tantas ocorrências interessantes observadas, a prática da discriminação sendo definida pela aparência das pessoa se destaca. Os bonitos são bajulados e os feios, gordos, desajeitados são rejeitados na escola privada. $\mathrm{Na}$ escola pública, os fortes e obesos são temidos. $\mathrm{Na}$ escola privada, o domínio é exercido pelos belos e, na pública, pelos fortes e corpulentos. 0 poder dos belos se assenta na sedu ção, na ostentação, na arrogância da consciência de sua condição privilegiada e eles são, na maioria das vezes, os agressores. Já o poder dos fortes se ancora na força, na imposição por meio da ameaça e da ef etiva agressão, geralmente, física. Vale um alerta: não se está, aqui, afirmando que um alu no seja vi o len to por queébo ni to, massim que a sua beleza acrescida de riqueza Ihe concede cacife suficiente para sobrepor-se aos demais. Um ponto em comum evidenciou-se entre as duas escolas: os feios são rejeitados.
A intolerância ao diferente é uma das faces do processo que dá origem à violência. Do outro lado pode surgir um outro tipo de conduta: os diferentes, isoladamente ou em grupo (no qual se identificam na diferença), respondem com agressão àqueles que os discriminam.

A realidademostrou-sediversanasduas escolas. Enquanto no Colégio $B$ a experiência da violência nasce, basicamente, da intolerância ao diferente, na Escola $A$, os discriminados pela diferença reagem praticando a violência.

As diferenças que marcam e determinam as discriminações nessa escola pública não são as mesmas da escola religiosa. Naquela, os diferentes eram marcados principalmente pela etnia e pela classe social, mas nesta os diferentes são aqueles que não se integram ao projeto pedagógico da escola e se vol tam con tra ela. Na Esco la A há uma di vi são que resulta em dois blocos: de um lado, o grande bloco dos integrados e participantes do projeto da escola, formado pelos professores e pela maioria dos alunos, e, de outro, o pequeno bloco que não responde ao projeto, cria uma vida própria e é formado pelos que são definidos pelos demais agentes da instituição como os que não querem saber dos estudos, os indisciplinados, os bagunceiros, os maus alu nos, osqueatra pal ham o desen vol vimento das atividades pedagógicas, os depredadores, os pichadores, os violentos, enfim, os que infernizam a vida da escola. Esse segun do gru po rea gea essa re jei ção ea essa discriminação construindo a violência - nos espaços onde a instituição é fraca - , que é dirigida, em várias ocasiões e indiscriminadamen te, con tra os pa res em ge ral econ tra o patrimônio. Os alvos, quando escolhidos, são os homossexuais masculinos e os negros (e nesses casos, caem na intolerância ao diferente na etnia e na orientação sexual). Esses alunos se esforçam para marcar e ressaltar suas diferenças, exagerando e ostentando um estilo 
próprio de movimentar o corpo, de se vestir, de falar e, principalmente, de se comportar.

As práticas da violência nas escolas não acontecem de uma forma só e não seguem sempre os mesmos rituais. Elas apresentam faces, tempos e particularidades sutis, e tudo dependendo do cenário onde se apresentam.

Observou-se que no Colégio $B$ há um cenário mais propício para as práticas sutis e escondidas da violência que necessitam de más ca ras, eque, naEsco la A, o cená rio permi tea expressão mais declaradadaviolên cia. Mas, com ou sem máscaras, as práticas da violência nunca deixam de se manifestar nas duas instituições.

É comum a idéia de se equacionar a violência com o mal. Para fugir de um julgamento, 0 ator, ao praticá-la, se serve de disfarces que tornam possíveis sua dissimulação. Transportando essa situação para as escolas, verificou-se que, na verdade, o artifício do mascaramento nãoépri vilégio apenasdospro tago nistas. Explicitando: os alunos se utilizam da máscara para que os adultos não percebam. Entretanto, esse ar ti fício não vale para os pa res, pelo con trá rio, já que um dos possíveis objetivos do ato violento é justa men teo deseexi birpara con seguira ad miração e a aceitação de seu grupo de identidade. Nem sempre a máscara garante a não percepção dospro fesso res. Hámo men tosem queépossí vel perceber que 0 adulto tem a percepção de que a prática da vio lên cia está seefetu an do, masfinge que não está vendo. Se esse jogo de faz-de-conta estiver realmente acontecendo, então, há uma nova máscara em ação e, nesse caso, ela foi colocada no ato praticado pelo pró prio professor. E o aluno entra no ardil e também faz de conta que está acreditando que 0 adulto não está vendo. Observa-se que há um teatro com fingimentos de ambas as partes.

Às vezes, a violência acontece de forma súbita, sem prelúdios. Em outras ocasiões, antes de acontecer, ela se aloca em espaços ou estágios prévios, como se fossem ante-salas. A ante-sala pode, ou não, oferecer um ambiente propício. Quando as condições se apresentam favoráveis, o ato que ainda não era violência ganha no vas con formaçõese passaparaa sala, onde já pode se manifestar com feições de violência. Na ante-sala se estabelecem atos como ain disciplina ou as brincadeiras de mau gosto.

As fronteiras entre a ante-sala e a sala ou os espaços típicos da violência são tênues e o trânsito dessa passagem nem sempre são percebidos. Não existe uma passa gem tão clara que permita que se defina que isto ou até aqui é violência e que até lá ou aquilo não é violência. 0 que ocorre é que os significados vão se misturando na prática e, como o processo evolui rapidamente, nem sempre é possível definir o momento que a violência explo diu. Um epi só dio ba nal podesetransformar e acabargeran do uma situ a ção com plicada e constrangedora.

Um exemplo que clarifica a compreensão: a atribuição de apelidos é encarada como brincadeirapor quem 0 atribui, mas nem sem pre por quem o recebe. ${ }^{10}$ No início, tudo é brincadeira de quem quer se divertir provocan do e ir ri tan do o co lega, efica restri taà ante-sala. No momento seguinte, ao vir a resposta do aluno visado, com pontapés e atracamento de corpos, ocorre a transferência para a sala da violência.

Esse caso dos apelidos ilustra as ante-salas das brincadeiras de mau gosto que podem se encerrar nelasmesmas, mas quepodem culminar num dano interno grande ou num desenlace de agressão física.

10. Há apelidos que indicam intimidade e são carinhosos. Entretanto, há outros, pejorativos, que o receptor considera ofensivos. Em geral, os apelidos rejeitados pelos recebedores são aqueles fazem referência à origem étnica, à orientação sexual, à condição social e a traços que evidenciam o que é considerado "falha", "defeito" e "carência". Alguns dos apelidos citados por alunos que se sentem ofendidos foram: Loira burra (para uma menina loira, muito bonita e repetente), Girafa e Carla Perez (para um menino com trejeitos femininos), J amanta (para um outro considerado homossexual, muito feio e "sonso"), Negresco, Macaca, J apona (para alunos negros e japoneses), Favelado(a) (para alunos que não têm comportamento de acordo com a etiqueta e para alunos que residem em bairros populares distantes das escolas), Pão-de-ló (para um filho de padeiro, portanto, sem prestígio social) e outros mais. 
Todos os estudiosos reconhecem que brigas corpo raiseati vida des lú di casexistemeque sempre fizeram parte da vida das crianças e adolescentes. A diferença que deve ser reconhecida entre o passado e o presente é a rapidez do trânsito para um desenlace grave.

\section{Considerações fina is}

Os mecanismos da socialização atuantes, hoje, no ambiente escolar estão permitindo a entrada das dificuldades da vida coletiva do país e do mun do, asqua isgeram preconceitose discriminações porque a própria instituição não está conseguindo imprimir um outro padrão. Na verdade, ela está simplesmente assimilando, sem filtro, o padrão da vida social coletiva. A conseqüência desse esta do deco isas é a formação de jovens alunos que se mostram pessoas desprovidas da idéia de alteridade, do espaço democrático, do diálogo, do convencimento ou da persuasão. $E$, como num círculo vicioso, o resultado disso é a manutenção e até o fortalecimento de uma sociedade muito pouco democrática.

Se o que se deseja é uma política de educa ção com mais demo cracia, en tão épre ci so repensar a escola, analisar o seu currículo e redi recio nar assuasações paraqueseja su perada essa crise da socialização. 0 primeiro passo em direção a uma mu dan çadecon du tano co tidiano é a conscientização e a compreensão dessas dificuldades da vida coletiva. Neste sen tido, seria importante estender a ênfase dos conceitos simplesmente pedagógicos até os (pré)conceitos que fomentam as práticas do cotidiano. Essa maior abrangência significa 0 transporte da vida do mundo relacional até 0 mundo pedagógico, ou seja, a inclusão, no currículo, da reflexão, da discussão e do entendimento de conceitos como identidade (cultural e social), alteridade, diferença, multiculturalismo, gênero, etnia, sexualidade, intolerância, preconceito, discriminação, violência, dentre tantos outros.

Tal discussão remete à problemática do modo como o professor deveria atuar na sala de aula, às dificuldades, ao despreparo eà fal ta de formação inicial e continuada. Essas deficiências, que não são do professor, mas dos próprios mecanismos institucionais, se mostram na própria forma de trabalho escolar ou no modo como a própria cultura escolar está organizada. Os cursos de Pedagogia e Licenciatura ignoram e raramente discutem questões do dia-a-dia das escolas, como a indisciplina, a violência, os preconceitos, as discriminações ou as relações que irão construir com os alunos, pois as preocupações estão voltadas para o estritamente pedagógico, como os planejamentos, ou para as teorias da educação ou da psicologia. A falha de formação propicia aos profissionais, em sua maioria, o desconhecimento de quais caminhos percorrer e como lidarcomessa pro blemática. Essa situação pede a sugestão de mudança de currículo que não deve se restringir apenas às escolas terminais da cadeia educacional. Ela deve, isto sim, se iniciar nos cursos formadores de profissionais da educação.

\section{Referências bibliográficas}

ABRAMOVAY, Miriam et al.. Gangues, galeras, chegados e rappers: juventude e cidadania nas cidades da periferia de Brasília. Rio de J aneiro: Garamond, 1999.

APPLE, Michael. Educação e poder. Porto Alegre: Artes Médicas, 1989.

CAMACHO, Luiza Mitiko Yshiguro. Violência e indisciplina nas práticas escolares de adolescentes: um estudo das realidades deduas es colassemelhantes ediferentes entresi. São Paulo;2000.265p. Tese (Dou to rado)- Faculda de de Educação da USP. 
CAMACH0, Thimoteo. Educa çãoe po der de Michael Apple. RevistadaFaculdadedeEducação, São Pa u lo, v.16, n. 1 e 2, p. 169-178, jan/dez. 1990.

CANDAU, Vera Maria et al. Escola e violência. Rio de J aneiro: DP\&A., 1999.

CHARLOT, Bernard. e ÉMIM J ean-Claude (Coord.). Violences à l'école: état des savoirs. Paris: Armand Colin, 1997.

CHAUI, Ma rilena. Éticaeviolência. Teoria\&Debate, São Pa u lo, Fun da ção Per seu Abra mo, n. 39, p 32-41, out/nov/dez. de 1998.

Uma ideologia perversa. Folha de S. Paulo, São Paulo, 14.03.1999.

CODO, Wanderley(coord.). Edu cação: ca rinhoetra ba Iho. Burnout, a sín dro me da de sis tên cia do edu ca dor, que pode le var à falência da educação. Petrópolis: Vozes, 1999.

DEBARBIEUX, Éric. La violence dans la classe. Paris: ESF, 1990.

. La violence en milieu scolaire: État des lieux (1). Paris: ESF,1997.

. Leprofesseuretlesauvageon: violenceàl'école, incivilitéetpostmordernité. RevueFrançaise de Péda go gie. La violence à l'école; approches européenes. Paris: Institut National de Recherche Pédagogique, n. 123, p. 7-19, avril/mai/juin, 1998.

.GARNIER, Alix; MONTOYA, Yves e TICHIT, La u rence. Lavio lenceen milieuscolaire: Ledésordredes choses (2). Paris: ESF, 1999. 190p.

DUBET, François. Les lycéens. Paris: Seuil, 1991.

Sociologie de l'expérience. Paris: Seuil, 1994.

. e MARTUCCELLI, Danilo. A l'école: Sociologie de l'expérience. Paris: Seuil - CADIS, 1995.

. Les figures de la violence à l'école. Revue Française de Pédagogie. La violence à l'école: approches européenes.. Paris: Institut National de Recherche Pédagogique, n. 123, p. 35-45, avril/mai/juin. 1998.

241-266, 1997.

DURKHEIM, Émile. L'éducation morale. Paris: Librairie Félix Alcan, 1925.

ELIAS, Norbert. 0 processo civilizador: a formação do Estado e civilização, vol. 2, Rio de J aneiro: J orge Zahar, 1996.

ERIKSON, Erik H. Identidade: juventude e crise. Rio de J aneiro: Guanabara, 1987.

GALLAND, Olivier. Les jeunes et la violence. Les Cahiers de la sécurité, Paris, IHESE, n. 5, p. 13-25, mai/juillet 1991.

GUIMARÃES, Áurea M.. Escola e violência: relações entre vigilância, punição e depredação escolar. Campinas; 1984. Dissertação (Mestrado) - PUC. A depredação escolar e a dinâmica da violência. Campinas; 1990. Tese (Doutorado) - UNICAMP.

GUIMARÃES, MariaEloisa. Escola, galeras enarcotráfico. Rio de J aneiro; 1995. 205p. Tese (Doutorado) - Departamento de Educação da PUC.

MARGULIS, Ma rio e URRESTI, Marce lo. La ju ven tud es más que una pa la bra. In: MARGULIS, M. (Org.). La ju ven tud es más que una palabra. Buenos Aires: Biblos, 1996.

MARTUCCELLI, Danilo. Reflexões so bre a vio lênciana con di çãomoderna. Temposocial, Revis tadeSo ciologia daUSP, São Paulo, n. 11, p. 157-175, maio, 1999. 
MELUCCI, Alberto e FABBRINI, Anna. L'etá dell'oro: adolescenti tra sogno ed esperienza. Milano: Feltrinelli, 1992.

MINAYO, Maria Cecília de Souza et al. Fala, galera: juventude, violência e cidadania. Rio de J aneiro: Garamond, 1999.

NOGUEIRA, Maria Alice. Trajetórias escolares, estratégias culturais e classes sociais: notas em vista da construção do objeto de pesquisa. Teoria \& Educação, Porto Alegre: Pannonica, $\mathrm{n} \cong 3,1991$.

. Aes colha do es ta belecimento de en sino pelas fa mílias: aaçãodis creta dariquezacultural. RevistaBrasileirade Educação; São Paulo, ANPEd., n. 7, p. 42-56, jan/fev/mar/abril, 1998.

OLIVEIRA, Francisco de. Medusa ou as classes médias e a consolidação democrática. In: O'DONNELL, G e REIS, F.W. (Orgs.). Dilemas e perspectivas da democracia no Brasil. São Paulo: Vértice, 1988.

OLIVEIRA, CláudiaRegina. O fe nôme no da vio lên cia em duas es colas: um es tu do decaso. PortoAlegre; 1995. Dissertação (Mestrado) - UFRGS.

PERALVA, AngelinaTeixeira. Aclas semédia re dis cutida- uma his tó ria de lu tas socia is no Brasil. Pa ris; 1985. 134p. Tese (Doutorado) - Institut d'Etude du Développement Economique et Social da Université de Paris I - Sorbonne.

. Escolaevio lêncianas pe riferias urba nas francesas. ContemporaneidadeeEducação, Rio deJ a nei ro, Instituto de Estudos da Cultura e Educação Continuada, n. 2, p. 7-25, set. 1997.

L'incivilite, la revolte et le crime: violences juveniles dans la societé de risque. Paris, 1997, 434p. Dossiê (Habilitaçãa para dirigir Pesquisas Sociológicas) - École des Hautes Etudes en Sciences Sociales.

PIERUCCI, AntônioFlávio. Ciladasdadiferença. São Pau lo: Curso de Pós-Graduaçãoem Sociolo gia da Universida de de São Paulo/34, 210p.,1999.

SPOSITO, Marilia Pontes. A instituição escolar e a violência. Cadernos de pesquisa, São Paulo: Fundação Carlos Chagas/Cortez, n. 104, 1998.

TOURAINE, Alain. Production de la société. Paris: Seuil, 1973.

VALIENTE, Enrique. Anorexia y bulimia: el corsé de la autodisciplina. In: MARGULIS, Mario. La juventud es más que una palabra. Buenos Aires: Biblos, 1996.

WAISELFISZ, J ulio J acob (coord.). J uventude, violência e cidadania: os jovens de Brasilia. São Paulo: Cortez, 1998. Mapa da Violência II: os jovens do Brasil. Brasília: Unesco, 2000.

WRIGHT MILLS, C.. A nova classe média. Rio de J aneiro: Zahar, 1976.

ZIMERMAN, David E. Gru pos es pon tâ neos: as tur mas e gan gues de adoles cen tes. In:ZIMERMAN, D. E. e OSORIO, L.C. e colaboradores. Como trabalhamos com grupos. Porto Alegre: Artes Médicas, 1997.

Recebido em 12.07.01 Aprovado em 04.09.01

Luiza Mitiko Y. Camacho é Professora do Departamento de Didática e Prática de Ensino e do Programa de Pós-Graduação em Educação do Centro Pedagógico da Universidade Federal do Espírito Santo. 